ISSN 0258-7122 (Print), 2408-8293 (Online)

Bangladesh J. Agril. Res. 44(2): 311-326, June 2019

\title{
PREDICTION OF CHANGING CLIMATIC EFFECT AND RISK MANAGEMENT BY USING SIMULATION APPROACHES FOR RICE- WHEAT SYSTEM IN BANGLADESH
}

\author{
M. K. HASAN ${ }^{1}$, S. AKHTER ${ }^{2}$, M. A. H. CHOWDHURY ${ }^{3}$ \\ A. K. CHAKI ${ }^{4}$, M. R. A. CHAWDHERY ${ }^{5}$ AND T. ZAHAN ${ }^{4}$
}

\begin{abstract}
A study was carried out on the impact of climate change in rice-wheat systems on farmers' livelihood in Dinajpur region of Bangladesh to evaluate the usefulness of the implication of simulation approaches to predict climate change effect and to manage risk for this cropping system. Trade-off analysis for multidimensional impact assessment (TOA-MD) model was used in the study with a combination of simulated baseline production and future simulated yield using Decision Support Systems for Agro-technology Transfer (DSSAT) and Agricultural Production Systems SIMulator (APSIM) in rice and wheat production system. Five different climate scenarios of Global Circulation Models (GCMs) were considered. The projections showed to have a negative economic impact between 50 and $82 \%$ for the difference in the magnitude and in the impact of different GCMs which was not possible to overcome. The survey revealed that northwest region of Bangladesh is likely to be affected by climate change and has high levels of vulnerability due to limited access to alternative livelihood activities other than farming. Simulation results showed no additional economic gain from wheat cultivation under changed climatic conditions, but increased economic profit was obtained from rice cultivation due to increased productivity trend. Therefore, study suggests an adaptation package of $50 \mathrm{~mm}$ additional irrigation water for wheat cultivation that could be an appropriate strategy to mitigate climate change risk in wheat cultivation. This practice had a positive impact on projected per capita income gains of about $2.05 \%$ in the study area and reduced poverty rate by about $1.99 \%$. The study also revealed that prediction of the APSIM model for adaptation impact of climate change on economic return and per capita income of farmers was superior to DSSAT model.
\end{abstract}

Keywords: Climate change, Crop modeling, Simulation, Risk management.

${ }^{1}$ Chief Scientific Officer, Agricultural Statistics and ICT Division, Bangladesh Agricultural Research Institute (BARI), Gazipur-1701, ${ }^{2}$ Principal Scientific Officer, Soil Science Division, BARI, Gazipur-1701, ${ }^{3}$ Former Director (Computer and GIS), Bangladesh Agricultural Research Council (BARC), Dhaka-1215, ${ }^{4}$ Scientific Officer, On-Farm Research Division, BARI, Gazipur-1701, ${ }^{5}$ Former Research Fellow, AgMIPIGB Project, Bangladesh Component, BARC, Dhaka-1215, Bangladesh. 


\section{Introduction}

Agriculture is a vital driver of the economic growth of Bangladesh. The contribution of this sector to gross domestic product (GDP) is $15.33 \%$ (BBS, 2017). Besides, about $43.6 \%$ of the total labour force of the country is engaged in this sector. Rice (Oryza sativa) plays a pivotal role in all spheres of life in Bangladesh to meet food demand. Wheat (Triticum aestivum L.) is the third most important cereal and playing significant role in food security. Rice is grown in three distinct seasons- Aus (pre-monsoon season), Aman (rainy season) and Boro (winter season) while wheat is grown only in winter season. During last 40 years cereal production has increased more than triple and this increasing trend has achieved mainly due to the yield increase of the cereals. The current coverage of rice and wheat is 11.42 million and 0.44 million hectares to produce 34.71 million and 1.35million tonnes respectively (BBS, 2016). The total land area of the country is 14.84 million hectares with average cropping intensity of about $191 \%$ (BBS, 2016). The dominant cropping pattern of the country is rice-rice system followed by rice-wheat system.

Bangladesh is one of the most climate vulnerable countries of the central and eastern Indo-Gangetic Basin (IGB) in respect of many environmental hazards like frequent flood, drought, storm and cyclone that damage life, property and agricultural production. The acceleration of the agricultural production may become difficult due to climate change that could fail to meet the increasing food demand of the country. Several studies have been done in Bangladesh on impacts of climate change, but study results focus on climate projections without quantifying agricultural impacts, even those reports tend to examine just a subset of the impact factors.

Simulation studies were carried out by Hussain (2010) for rice and wheat using the CERES-Rice and CERES-Wheat models to assess the impact of climate change on Bangladesh agriculture. In most cases detrimental effect of temperature rise was observed with elevated $\mathrm{CO}_{2}$ levels. Wheat is more susceptible to high temperature than rice. Increase of temperature generally reduces crop production across all scenarios. Change in precipitation either has a positive or a negative impact with a high degree of uncertainty across Global Climate Models (GCM). The impact of climate change on cereals and on food security has been studied by several researchers, but effort on integrating cropping systems with other income-generating activities has not been made under Bangladesh condition. Therefore, this study was undertaken as a component of the IGB regional assessments following Agricultural Model Inter-comparison and Improvement project (AgMIP) protocols and integrated assessment procedures to assess the impacts of climate change in rice-wheat system by generating reasonable estimates and also to project future climatic effect for risk management. 


\section{Materials and Method}

\section{Location and farming system}

Dinajpur district was considered as the study area which is situated at the northwest partof Bangladesh located in between $25^{\circ} 22^{\prime}$ and $26^{\circ} 06^{\prime}$ north latitudes and in between $89^{\circ} 31^{\prime}$ and $88^{\circ} 38^{\prime}$ east longitudes. The total area of this district is $3,437.98 \mathrm{~km}^{2}$. Rice-wheat is the dominant cropping system that occupies a major portion of that region (Sarker et al., 2014).

The annual average highest temperature of Dinajpur district was $33.5^{\circ} \mathrm{C}$ and the lowest was $10.5^{\circ} \mathrm{C}$ with annual rainfall of $2536 \mathrm{~mm}$. Soil profile-wise data were compiled from different Reconnaissance Soil Survey Reports (SRDI, 2016). A Total of 45 different soil series profiles (i.e., AGMIP13001, AGMIP13002 to AGMIP13045) were created as input for DSSAT and APSIM models. The area coverage of rice and wheat in Dinajpur district is 0.77 million and 0.023 million hectares; and production is 2.42 million and 0.072 million tonnes, respectively (BBS, 2017). Double cropped Rice-Wheat system is dominant in that region which covers about $67 \%$ of total area.

\section{Representative Agricultural Pathways (RAPs)}

The Representative Agricultural Pathways (RAPs) is an overall narrative description of a plausible future development pathway that contains key variables with qualitative storylines and quantitative trends, consistent with higher-level pathways (Valdivia and Antle, 2014). These scenarios represent a set of technology and management of adaptations to climate change.

A day-long workshop was organized to develop RAPs and reviewed the current and future changes in agricultural practices and in socio-economic aspects regarding of climate change. Forty-three participants from National Agricultural Research System (NARS) Institutes, Bangladesh Meteorological Department (BMD) and civil society were participated in the workshop. After threadbare discussion final version of the RAPs was adopted. The finalized RAPs during the workshop were used for TOA-MD analysis. This helped to answer three core questions as selected by AgMIP for Integrated Regional Assessment. The questions were the followings:

1. What is the sensitivity of current agricultural production systems to climate change?

2. What is the impact of climate change on future agricultural production systems?

3. What are the benefits of climate change adaptations? 
The considerations for having answer of three core questions are given in Table 1.

Table 1.The considerations for having answer of the three core questions

\begin{tabular}{l|l|l}
\hline Core question & System-1 & System-2 \\
\hline Question-1 & $\begin{array}{l}\text { Production system in Current } \\
\text { Period (2010) with Current } \\
\text { Climate }\end{array}$ & $\begin{array}{l}\text { Production system in current } \\
\text { period (2010) with Future } \\
\text { Climate }\end{array}$ \\
\hline Question-2 & $\begin{array}{l}\text { Production system in Future } \\
\text { Period (2040) with Current } \\
\text { Climate } \\
\text { Productivity and Price trends } \\
\text { with no climate change and } \\
\text { RAPS }\end{array}$ & $\begin{array}{l}\text { Production system in Future } \\
\text { Period (2040) with Future } \\
\text { Climate } \\
\text { Price trends with climate change } \\
\text { and RAPS }\end{array}$ \\
\hline Question-3 & $\begin{array}{l}\text { Production system in Future } \\
\text { Period (2040) with Future } \\
\text { Climate } \\
\text { Price trends with climate } \\
\text { change and RAPS }\end{array}$ & $\begin{array}{l}\text { Adapted production system in } \\
\text { Future period (2040) with } \\
\text { Future Climate } \\
\text { Price trends with climate } \\
\text { change, RAPS and Adaptation } \\
\text { Package }\end{array}$ \\
\hline
\end{tabular}

RAPs parameters for Bangladesh agriculture were developed by consultation in meetings with the relevant stakeholders.

\section{Climate and climate projections}

Daily agro-meteorological data (daily maximum and minimum temperature, daily sunshine hour, etc.) of historical time series (1980-2009) were collected from BMD. Since the model requires solar radiation data $\left(\mathrm{MJ} / \mathrm{m}^{2} /\right.$ day $)$, bright sunshine data were converted to solar radiation based on Allen et al. (1998).

To assess the impact of future climate scenarios and to make inter-comparisons between APSIM and DSSAT for rice and wheat, yield performance at base 30 years weather was compared with 30 years of future climate scenarios. This was carried out using six sets of climate data, one (OXXX) for current climate and the other five (IEXA, IIXA, IKXA, IOXA, IRXA) scenarios with elevated $\mathrm{CO}_{2}$ at $571 \mathrm{ppm}$.

Besides the observed (OXXX) climate of 30 years (1980-2009), twenty GCMs data were generated using the AgMIP Climate Scenario Generation Tools with R (ACSGTR 2.1) for RCP 8.5 (2040-2069 time period; Mid-Century). Five other climate data sets (GCM-based climate change scenarios using mean-only delta scenarios) namely-IEXA, IIXA, IKXA, IOXA, IRXA for the median future scenarios were chosen for conducting the crop simulation runs. 
Where, the first letter stands for RCP 8.5 (2040-2069 time period; Mid-Century);

$\mathrm{E}=\mathrm{CCSM} 4, \mathrm{I}=\mathrm{GFDL}-\mathrm{ESM} 2 \mathrm{M}, \mathrm{K}=\mathrm{HadGEM} 2-\mathrm{ES}, \mathrm{O}=\mathrm{MIROC} 5, \mathrm{R}=\mathrm{MPI}-\mathrm{ESM}-$ $\mathrm{MR}$ and type of scenario: $\mathrm{X}=\mathrm{Observations}$ (no scenario) and $\mathrm{A}=$ Mean change from GCM.

For RCP8.5 Mid-Century 2040-2069 scenarios $\mathrm{CO}_{2}$ concentration was set at 571 ppm. Compared to the baseline (1980-2009) all the GCMs showed higher temperature in all months and the deviations among different GCMs were also observed. Winter (December-February) followed a similar pattern irrespective of CGMs. All the GCMs predicted higher summer temperature. In case of rainfall, less rainfall was predicted during the winter months (November to January) and more during the monsoon (mid-June to mid-October). Besides the above five GCMs, another 15 climate scenarios were also generated. It was evident that all 20 Mid-Century scenarios predicted higher maximum and minimum air temperatures during February and March compared to the baseline. It is presumed that such high temperature may cause yield reduction in wheat. To offset the impact of climate change and reduce the variability in wheat yields an adaptation strategy was incorporated in this study. Although, there were several adaptation strategies suggested in the RAPs development workshop, only one i.e., addition of one irrigation amounting $50 \mathrm{~mm}$ for wheat was used. Accordingly, both APSIM and DSSAT wheat models were used to generate the outputs under different GCMs.

Rainfed rainy season rice: The simulations run using DSSAT CERES-Rice and APSIM-Rice models (APSRU, 2012). The cultivated rice variety of the studied area was BR11 (transplanted rainy season rice) which was planted during 15-30 July, 2010. Seedlings of 25-35 days old were transplanted with 20 $\mathrm{cm}$ row spacing at the cultivation depth of $4 \mathrm{~cm}$. The density of rice seedlings was 25 plants per square meter with three plants per hill. Nitrogen was applied in three splits. The first split was as basal @ 27-40.5 kg/ha with a placement depth of $10 \mathrm{~cm}$ and another two splits were @ 39-46 kg and 39-46 $\mathrm{kg} / \mathrm{ha}$ as top-dress at 15 and 45 days after planting, respectively. The yield potentiality of BR11 is 5.5 ton per hectare (Chowdhury et al., 2013) having 145 days life duration.

Irrigated wheat: The simulations were carried out with DSSAT CERES-Wheat and APSIM-Wheat models. The cultivated wheat variety of that area was BARI Gom-21 (Shatabdi) which was sown during 11 November to 7 December, 2010 (winter season). The cultivation depth was $4 \mathrm{~cm}$ and the final crop stand was 200 plants per square meter. Nitrogen was applied in three splits. First split was as basal @ 30-40 kg/ha with a placement depth of $10 \mathrm{~cm}$ and another two splits were @ 25-35 kg/ha and 25-40 kg/ha as top-dress at 25 and 55 days after sowing, respectively. Three flood irrigations were provided at 20,45 and 75 days after sowing to keep the soil moist at field capacity. The 
yield potentiality of this variety is 3.5-5.0 t/ha (Chowdhury et al., 2013) with 109-112 days life duration.

\section{Household survey}

For integrated assessment through household survey was also carried out during May-September 2013 to collect data from randomly selected 50 farms from four Upazilas (sub-districts) of Dinajpur district to cover the major cropping pattern i.e. Rice (transplanted in rainy season) - Wheat (sowing in winter season) pattern. A pre-designed questionnaire (Table 2 and Table 3) was used in this purpose.

\section{Crop-model calibration (DSSAT and APSIM)}

Although the AgMIP project deals with the inter-comparison of various simulations models for different crops andtheir sensitivity, locations, etc.,this report considered only two crops (rice and wheat). Crop models used in the studywere: CERES-Rice and CERES-Wheat for DSSAT Ver. 4.5.1.023-Stub and APSIM 7.5-Oryza and APSIM-Wheat for each location.

\section{Results and Discussion}

\section{Crop model results (DSSAT and APSIM)}

Higher yields compared to the observed yields were predicted by both the models. The uncertainty in yields associated with different farms was more in case of APSIM compared to DSSAT. Both models over-estimated the yields. When inter-comparison was made between two wheat models (DSSAT-CERESWheat and APSIM-Wheat) higher yields were predicted by DSSAT-CERESWheat. In case of APSIM-wheat, less than $3500 \mathrm{~kg}$ per hectare yield was predicted at 55\% cumulative probability level which was lower than the observed yields. However, the uncertainty in yields associated with different farms was more in case of APSIM compared to DSSAT. Differences between the DSSAT and APSIM may be attributed to differences in sensitivity of the crop models. Simulated yields were higher compared to the farm survey yields and this might be happened as both the models did not consider pest and diseases effects on yield.

In case of rice, the maximum and minimum yield values predicted by APSIM for OXXX (historical), IEXA, IIXA, IKXA, IOXA, and IRXA scenarios were 8557, $7408,7267,5880,7538$ and $5492 \mathrm{~kg} / \mathrm{ha}$ and 6607, 5071, 4920, 3697, 5586, and $3718 \mathrm{~kg} / \mathrm{ha}$ with median values of 5904, 7472, 6003, 4749, 6533 and $4829 \mathrm{~kg} / \mathrm{ha}$, respectively. The DSSAT predicted maximum and minimum yields for OXXX, IEXA, IIXA, IKXA, IOXA, and IRXA were 7832, 7053, 7005, 6584, 7095 and $6483 \mathrm{~kg} / \mathrm{ha}$ and $3756,3703,3640,3652,3744$ and $4112 \mathrm{~kg} / \mathrm{ha}$ respectively. The median values according to the DSSAT model were 7185, 6630, 6503, 6107, 6710 , and $6152 \mathrm{~kg} / \mathrm{ha}$. 
Similarly, in case of wheat, median yields were higher for DSSAT-CERESWHEAT than APSIM-Wheat irrespective to climate scenarios. The future weather scenarios IEXA, IKXA, IRXA appeared to have depressive effects on wheat yield compared to the baseline scenario for DSSAT model. Conversely, the future weather scenarios appeared to have positive effects on wheat yield compared to the baseline scenario for APSIM model with higher farm to farm variability.

The APSIM predicted maximum and minimum wheat yield values for OXXX (historical), IEXA, IIXA, IKXA, IOXA, and IRXA scenarios were 5692, 5624, $6223,5879,6308$ and $6054 \mathrm{~kg} / \mathrm{ha}$ and 2878, 2825, 3547, 3175, 3621 and 3824 $\mathrm{kg} / \mathrm{ha}$ with median values of $3464,3398,4286,3780,4369$ and $4471 \mathrm{~kg} / \mathrm{ha}$, respectively. The DSSAT predicted maximum and minimum wheat yields for OXXX, IEXA, IIXA, IKXA, IOXA, and IRXA were 5507, 5299, 5369, 5204, 5548 and $5009 \mathrm{~kg} / \mathrm{ha}$ and 4036, 3470, 3452, 3380, 3649 and $3338 \mathrm{~kg} / \mathrm{ha}$ respectively. The median values were 4637, 4481, 4691, 4485, 4885 and 4426 $\mathrm{kg} / \mathrm{ha}$. APSIM showed that median yields increased with the adaptation irrespective of GCMs and also the variability in yields was reduced. Without adaptation baseline (OXXX) yields were 2878 to $5692 \mathrm{~kg} / \mathrm{ha}$ and with adaptation 2998 to $6434 \mathrm{~kg} / \mathrm{ha}$. While, IRXA gave the highest median yields without and with adaptation.

Similarly, DSSAT showed that median yields increased with the adaptation irrespective of GCMs and also the variability in yields was reduced. On the other hand, in case of DSSAT the simulated minimum and maximum yields for historic baseline (OXXX) without and with adaptation were 4036 and 5507, and 4112 and $5514 \mathrm{~kg} / \mathrm{ha}$ respectively. In contrast to APSIM, DSSAT under IRXA gave the lowest median yields without and with adaptation. The simulated minimum and maximum yields for this scenario varied between 3338 and 5009 $\mathrm{kg} / \mathrm{ha}$ without adaptation and with adaptation the values were 3338 and 5034 $\mathrm{kg} / \mathrm{ha}$, respectively.

\section{Key findings of household survey}

The average household size of Dinajpur was 5.74 persons against national average of 5.31 (BBS, 2013). The average farm size was 0.90 hectare. The average annual non-agricultural income was Tk.59600 per farm and contribution of crop component was Tk.40690 per farm annually. Average level of farmers education (year of schooling) was only about five years.

The study revealed that the average plot size for rice cultivation was 0.657 hectare. Majority of the farmers cultivated rice in medium high lands $(58 \%)$ followed by high land (26\%) and medium low land (16\%). On the other hand, majority of the rice plots having loam soil $(84 \%)$ followed by clay loam $(6 \%)$. Regarding input use in rice cultivation, on an average, farmers applied $150.15 \mathrm{~kg}$ nitrogen $(\mathrm{N}), 69.14 \mathrm{~kg}$ Triple super phosphate (TSP), $51.37 \mathrm{~kg}$ muriate of potash 
(MoP) per hectare. The standard recommendation for transplanted rainy season rice is $90-120 \mathrm{~kg} \mathrm{~N}, 80-100 \mathrm{~kg}$ TSP, $80-120 \mathrm{~kg} \mathrm{MoP}$ and $50-72 \mathrm{~kg}$ gypsum per hectare (FRG, 2012). They grew rice under rainfed condition. Seventy-four percent of the farmers applied pesticides twice and the remaining 26\% did not apply any pesticides in the rice. The farmers obtained $3826.24 \mathrm{~kg} / \mathrm{ha}$ grain yield which was little higher than the five years mean yield of rice $(3801.48 \mathrm{~kg} / \mathrm{ha})$ in Dinajpur (Table 2).

The average plot size for wheat in the surveyed farms was 0.404 hectare. Most of the farmers cultivated wheat in medium high lands $(58 \%)$ followed by high lands $(28 \%)$ and medium low lands $(16 \%)$. The texture of the soil of the wheat plots were loam $(84 \%)$ followed by sandy loam $(10 \%)$ and clay loam $(6 \%)$. For wheat cultivation, average input use per hectare were $2139 \mathrm{~kg}$ farmyard manure (FYM), $86.5 \mathrm{~kg} \mathrm{~N}, 84.3 \mathrm{~kg}$ TSP, $78.2 \mathrm{~kg}$ MoP, $20.2 \mathrm{~kg}$ gypsum, $1.83 \mathrm{~kg}$ zinc sulphate and $9.09 \mathrm{~kg}$ borax. While the standard recommendation of fertilizers for wheat is $81-99 \mathrm{~kg} \mathrm{~N}, 140-180 \mathrm{~kg}$ TSP, 40-45 kg MoP and 110-120 kg gypsum per hectare (BARI, 2011). Majority of the farmers (56\%) applied irrigation twice followed by thrice $(26 \%)$ and once (18\%). Fifty percent of the farmers applied pesticides twice, 22\% applied once and 6\% applied thrice in the crop season. The remaining $22 \%$ did not apply any pesticides in the wheat field. The farmers obtained 3346.3 $\mathrm{kg} / \mathrm{ha}$ grain yield which was much higher than the five years mean yield of wheat (2497 kg/ha) in Dinajpur (Table 3).

Table 2. Key statistics of base systems variable of rice (var. BR11) cultivation at Dinajpur during 2013

\begin{tabular}{l|c|c|c}
\hline Description & Mean & Stdev & CV (\%) \\
\hline Land type & HL-26\%, MHL-58\%, MLL-16\% & - & - \\
Soil type & $\begin{array}{c}\text { Loam-84\%, Sandy loam-10\%, Clay } \\
\text { loam-6\% }\end{array}$ & - & - \\
Human labour (man day/ha) & 173.0 & 7.59 & 4.40 \\
Mechanical cost (Tk./ha) & 2199.5 & 1487.76 & 67.64 \\
Seed rate (kg/ha) & 34.0 & 12.93 & 37.5 \\
N (kg/ha) & 150.2 & 25.98 & 17.30 \\
TSP (kg/ha) & 69.1 & 10.4 & 15.04 \\
MoP (kg/ha) & 51.4 & 6.27 & 12.2 \\
Irrigation (times) & Rainfed & - & - \\
Pesticides application (times) & $0(22 \%), 1(22 \%), 2(50 \%), 3(6 \%)$ & - & - \\
Observed grain yield (kg/ha) & 3826.2 & 460.29 & 12.03 \\
Mean grain yield (kg ha ${ }^{-1}$ per 5 & 2566.0 (clean rice) & - & - \\
years)* & Equivalent to 3801.5 & & \\
\hline
\end{tabular}


Table 3. Key statistics of base systems variable of wheat (var. Shatabdi) cultivation at Dinajpur during 2013

\begin{tabular}{|c|c|c|c|}
\hline Description & Mean & Stdev & CV (\%) \\
\hline Land type & HL-28\%, MHL-58\%, MLL-16\% & - & - \\
\hline Soil type & $\begin{array}{l}\text { Loam- } 84 \% \text {, Sandy loam-10\%, Clay } \\
\text { loam-6\% }\end{array}$ & - & - \\
\hline Human labour (man days/ha) & 143.78 & 14.51 & 10.09 \\
\hline Mechanical cost (Tk./ha) & 4593.1 & 1142.9 & 24.88 \\
\hline Seed rate $(\mathrm{kg} / \mathrm{ha})$ & 157.3 & 18.54 & 11.79 \\
\hline FYM (kg/ha) & 2136 & 2190.4 & 102.55 \\
\hline $\mathrm{N}(\mathrm{kg} / \mathrm{ha})$ & 86.5 & 45.16 & 23.49 \\
\hline TSP (kg/ha) & 84.3 & 22.87 & 33.07 \\
\hline MoP (kg/ha) & 78.2 & 35.19 & 45.02 \\
\hline Gypsum (kg/ha) & 20.2 & 27.64 & 137.02 \\
\hline Zinc sulphate (kg/ha) & 1.83 & 3.62 & 197.64 \\
\hline Borax (kg/ha) & 9.09 & 12.62 & 138.83 \\
\hline Irrigation (times) & $1(18 \%), 2(56 \%), 3(26 \%)$ & - & - \\
\hline Pesticides application (times) & $0(22 \%), 1(22 \%), 2(50 \%), 3(6 \%)$ & - & - \\
\hline Observed grain yield (kg/ha) & 3346.3 & 520.79 & 15.56 \\
\hline $\begin{array}{l}\text { Mean grain yield }\left(\mathrm{kg} \mathrm{ha}^{-1} \text { per } 5\right. \\
\text { years)* }\end{array}$ & 2497.0 & - & - \\
\hline
\end{tabular}

*Source: BBS, 2015

\section{Parameters emerged from RAPs}

A combination of increased population, government subsidy on fertilizers desired to improve economic status and also expected as the cause of shifting from agriculture to service in industry. The main RAPs parameters used in TOA-MD analysis are given below:

Farm and family size: From the historic data it was observed that farm and family size was decreasing over time. The consultation agreed that farm size would be decreased by $20 \%$ and family size would be decreased by $10 \%$ during the next 30 years.

Variable costs of production: Variable cost of agricultural products is increasing day by day. The average cost of production would be increased by $40 \%$ during next 30 years. 
Off-farm income: Off-farm income is also increasing rapidly and dependency on agriculture is decreasing day by day. During next 30 years it could be increased by $100 \%$.

Adaptation: The following adaptation strategies were finalized as per the participating stakeholders of the development workshop of RAPs.

- Seven days advancement of sowing date to avoid terminal heat stress for wheat.

- Improved fertilizer management and soil test based application in both rice and wheat.

- Use of short-duration rice varieties to facilitate early wheat sowing.

- Modification of irrigation dates and amounts for wheat.

Among the several adaptation strategies, only the increasing the irrigation strategy amounted by $50 \mathrm{~mm}$ per irrigation for wheat has been incorporated in this study.

\section{TOA-MD findings}

\section{Question 1: Climate Sensitivity}

The sensitivity of the current production system with changing climate in different climatic scenarios is presented in Table 4. It is evident from the table that under all five climatic scenarios the mean yield of rice would decline, and the change would be in the tune of -38.2 to $-13.6 \%$ with APSIM while from -14.7 to $-7.4 \%$ with DSSAT. In case of wheat with APSIM, the mean yield decrease is likely under three climate scenarios $(-2.0$ to $-9.0 \%)$ and showed increase in yield under two climate scenarios IEXA (1.0\%) and IRXA (2.0\%). On the other hand, DSSAT estimated $1.0 \%$ increase under IOXA climate scenario as well as a decline of -3.0 to $-9.0 \%$ with other four climate scenarios. The gain in mean net farm returns, however, was 12.9 to $15.8 \%$ higher with APSIM and 13.3 to $14.2 \%$ higher with DSSAT. The extent of losses as percent of net farm return was higher in APSIM $(24.8 \%$ to $10.2 \%)$ than in DSSAT $(16.5 \%$ to $11.6 \%)$. The net farm returns and per capita income decreases in all the climatic scenarios due to the climate change and the poverty level rises by less than $1 \%(0.04$ to $0.35 \%)$.

\section{Question 2: Impact of Climate Change in Future without Adaptation}

TOA-MD analysis was used to answer the Core Question 2 where the RAPs parameters and other estimates of productivity and price trends from global model were considered for rice and wheat. The analysis reveals that rice under all five climate scenarios gained yields in the tune of 20.0 to $28.0 \%$ with APSIM and 13.0 to $23.0 \%$ with DSSAT. In case of wheat, there would be a declining trend in yields for both the models. For APSIM and DSSAT the mean yield change would vary from -0.4 to $19.0 \%$ and from -1.0 to $-11.0 \%$, respectively. The net farm 


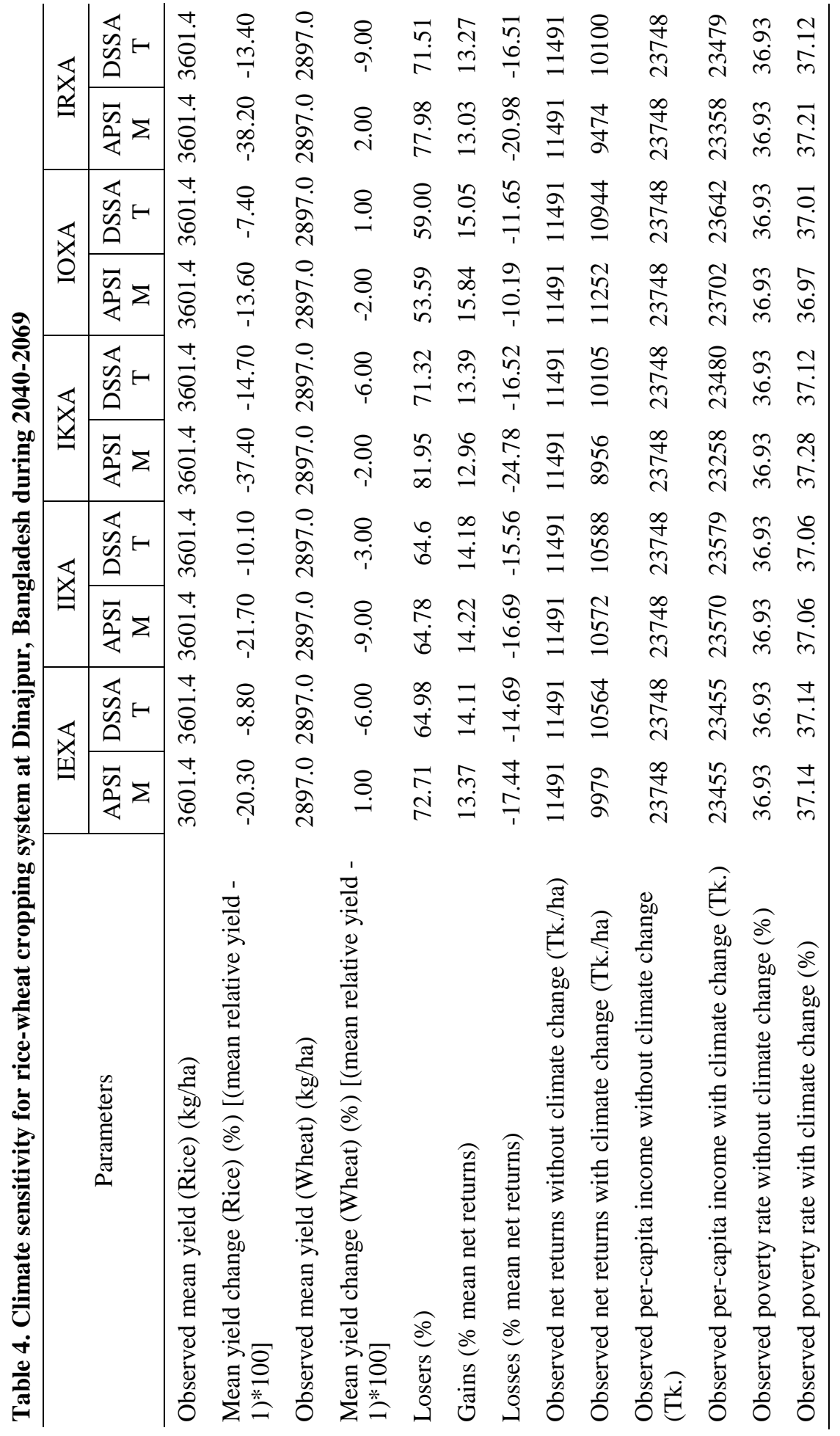




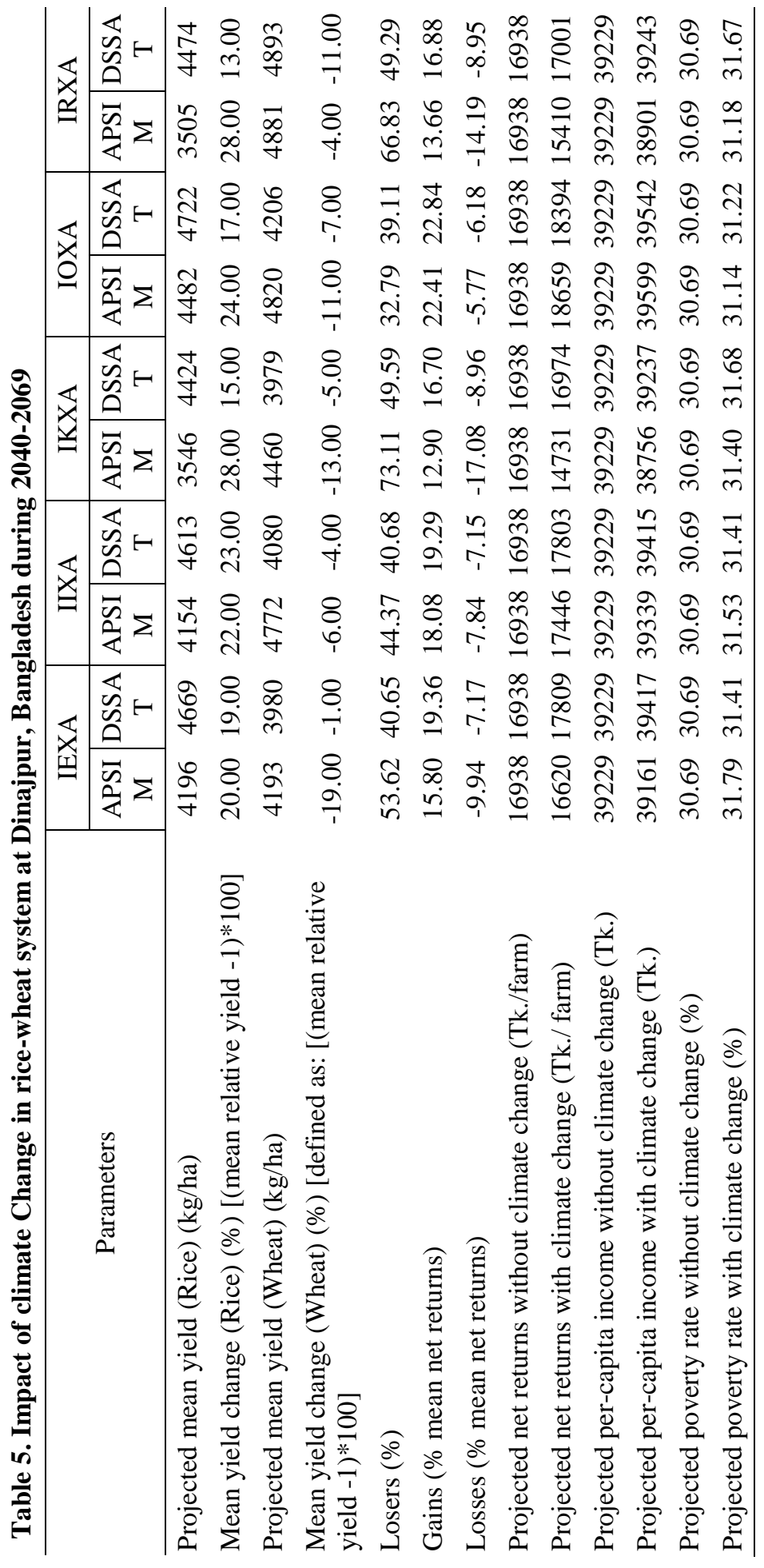




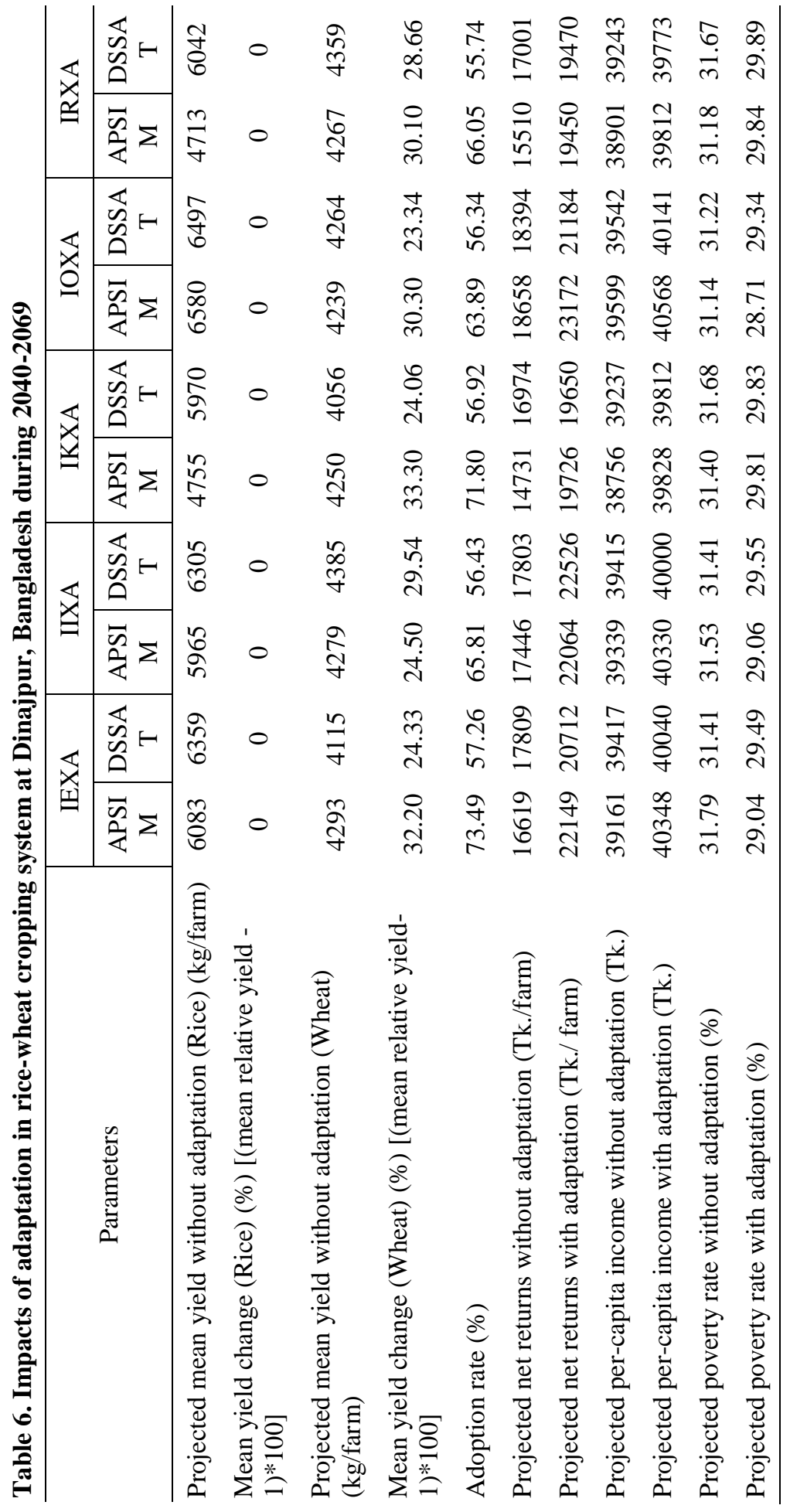


returns due to climate change increased with APSIM for all five climate scenarios while declined in net farm returns with DSSAT (Table 5). It could be due to the higher price of grains predicted by the impact model which increases the net farm return despite of lower yield in wheat; however, the net farm return decreased on an average. The per capita income also decreased in all the climatic scenarios due to the climate change and the poverty level raised by 0.5 to $1.1 \%$.

\section{Question 3: Impact of Climate Change in Future with Adaptation}

The impact of adaptation for climate change in rice-wheat system has described in Table 6. No adaptation measure for rice was undertaken as all the GCMs in changing climatic condition provided higher yields. On the contrary, adaptation package for wheat was undertaken and the summary results are presented in Table 7. The adaptation package for wheat in APSIM provided 24.5 to $33.3 \%$ gain in yields though DSSAT provided 23.3 to $29.5 \%$ gain in wheat yields. The adaptation package of wheat was likely to increase net returns and per capita income. The poverty level could fall by 1.3 to $2.8 \%$ in all the climatic scenarios while adapting the described climatic change scenarios there would be significant improvement in per-capita income. The magnitude of change in net returns and per capita income was likely to be higher with APSIM compared to that of DSSAT.

\section{Changes in production}

Simulation approaches predicted remarkable change in production of rice-wheat cropping system as mentioned in Table 7. Results demonstrated that predicted production of rice and wheat for question-1 was almost similar in case of both system approaches. But in case of question-2, predicted production of rice was found to increase remarkably and for question-3 predicted wheat production was much higher in system-2 when $50 \mathrm{~mm}$ additional irrigation was applied.

Table 7. Change in production of rice-wheat cropping system with three core questions

\begin{tabular}{l|l|l}
\hline Question & \multicolumn{1}{|c|}{ System-1 (APSIM) } & \multicolumn{1}{c}{ System-2 (DSSAT) } \\
\hline Question-1 & $\begin{array}{l}\text { Production system in Current } \\
\text { Period (2010) with Current } \\
\text { Climate } \\
\text { Rice: 3601 kg/ha; Wheat: } \\
2897 \mathrm{~kg} / \mathrm{ha}\end{array}$ & $\begin{array}{l}\text { Production system in current period } \\
\text { (2010) with Future Climate } \\
\text { Rice: } 2933 \mathrm{~kg} / \mathrm{ha} \text {; Wheat: } 2836 \mathrm{~kg} / \mathrm{ha}\end{array}$ \\
\hline Question-2 & $\begin{array}{l}\text { Production system in Future } \\
\text { Period (2040) with Current } \\
\text { Climate } \\
\text { Productivity and Price trends }\end{array}$ & $\begin{array}{l}\text { Production system in Future Period } \\
\text { (2040) with Future Climate } \\
\text { Price trends with climate change and } \\
\text { RAPS }\end{array}$ \\
\hline
\end{tabular}




\begin{tabular}{|c|c|c|}
\hline Question & System-1 (APSIM) & System-2 (DSSAT) \\
\hline & $\begin{array}{l}\text { with no climate change and } \\
\text { RAPS } \\
\text { Rice: } 4679 \mathrm{~kg} / \mathrm{ha} \text {; Wheat: } \\
4626 \mathrm{~kg} / \mathrm{ha}\end{array}$ & Rice: $5927 \mathrm{~kg} / \mathrm{ha}$; Wheat: $4250 \mathrm{~kg} / \mathrm{ha}$ \\
\hline Qu & $\begin{array}{l}\text { Production system in Future } \\
\text { Period (2040) with Future } \\
\text { Climate } \\
\text { Price trends with climate } \\
\text { change and RAPS } \\
\text { Rice: } 5927 \mathrm{~kg} / \mathrm{ha} \text {; Wheat: } \\
4250 \mathrm{~kg} / \mathrm{ha}\end{array}$ & $\begin{array}{l}\text { Adapted production system in Future } \\
\text { period (2040) with Future Climate } \\
\text { Price trends with climate change, } \\
\text { RAPS and Adaptation Package } \\
\text { Rice: } 5927 \mathrm{~kg} / \mathrm{ha} \text {; Wheat: } 5446 \mathrm{~kg} / \mathrm{ha}\end{array}$ \\
\hline
\end{tabular}

\section{Conclusion}

Climate change is likely to have adverse effects on the livelihoods of the smallholder farmers in Dinajpur district ranged between 50 and $82 \%$ that being affected and might not be able to cope up. Northwest region of Bangladesh is likely to be affected by climate change and has high levels of vulnerability due to limited access to alternative livelihood activities other than farming. Simulation results showed no additional economic gains from wheat cultivation due to decreasing yield trend by the years, but rice cultivation had increased yield and showed increasing trend of productivity. Therefore, an adaptation package of 50 $\mathrm{mm}$ additional irrigation water for wheat cultivation is likely to be an appropriate strategy for adapting to climate change. Moreover, both DSSAT-CERES-Wheat and APSIM-Wheat models predict more wheat yields than the observed yields, even DSSAT-CERES-Wheat model projects higher yield than APSIM-Wheat model. However, APSIM model is found less efficient to predict uncertainty in yields associated with different farms than DSSAT model. In case of predicting adaptation impact of climate change on economic return and per capita income of farmers, performance of APSIM model is superior to DSSAT model. Moreover, both models predict a positive impact of adaptation on projected per capita income that will be increased by about $2.05 \%$ and poverty rate will be reduced by about $1.99 \%$. Finally, this study appreciates the prediction capability of both simulation models that might be helpful for farmers to reduce the risk of climate change on agriculture of Bangladesh.

\section{Acknowledgement}

The authors are grateful to the Agricultural Model Inter-comparison and Improvement Project (AgMIP) for financing the research activities, and Dr. Sk. Ghulam Hussain, CIMMYT Consultant, AgMIP-IGB Project, Bangladesh Component for his persistent support and encouragement. 


\section{References}

Allen, R.G., L.S. Pereira, D. Raes and M. Smith. 1998. Crop evapotranspiration. Guidelines for computing crop water requirements, FAO Irrigation and drainage paper 56 (1998). Food and Agriculture Organization of United Nations, Rome, Italy.

APSRU. 2012. Agricultural Production Systems Research Unit. The Agricultural Production Systems SIMulator (APSIM) software is a modular modelling framework that has been developed by the APSIM Initiative and its predecessor the Agricultural Production Systems Research Unit (APSRU) in Australia.

BARI. 2011. Bangladesh Agricultural Research Institute.KrishiProjuktiHatboi (Handbook on Agro-technology in Bangla), 5th ed. Bangladesh Agricultural Research Institute, Gazipur-1701, Bangladesh.

BBS (Bangladesh Bureau of Statistics). 2013. Statistical Yearbook of Bangladesh-2011, $26^{\text {th }}$ ed. Statistics and Informatics Division, Ministry of Planning, Government of the People's Republic of Bangladesh, Dhaka, Bangladesh.

BBS (Bangladesh Bureau of Statistics). 2015. Yearbook of Agriculture Statistics-2013, $25^{\text {th }}$ series. Statistics and Informatics Division, Government of the People's Republic of Bangladesh, Dhaka, Bangladesh.

BBS (Bangladesh Bureau of Statistics). 2016. Statistical Yearbook of Bangladesh-2015, $35^{\text {th }}$ ed. Statistics and Informatics Division, Government of the People's Republic of Bangladesh, Dhaka, Bangladesh.

BBS (Bangladesh Bureau of Statistics). 2017. Statistical Yearbook of Bangladesh-2016. Statistics and Informatics Division, Government of the People's Republic of Bangladesh, Dhaka, Bangladesh.

Chowdhury, M.A.H. and M. S. Hassan. 2013. Handbook of Agricultural Technology. Bangladesh Agricultural Research Council, Farmgate, Dhaka-1215, Bangladesh.p.230.

FRG (Fertilizer Recommendation Guide). 2012. Bangladesh Agricultural Research Council, Farmgate, Dhaka-1215, Bangladesh.

Hussain, S.G. 2010. Assessing Impacts of Climate Change on Cereal Production and Food Security in Bangladesh. In: R. Lal et al., (Eds.), Climate Change and Food Security in South Asia, Chapter 28.Springer Science+Business Media B.V. DOI 10.1007/978-90-481-9516-9_28

SRDI (Soil Resources Development Institute). 2016.Annual Report 2015-16 (2016). Ministry of Agriculture, MrittikaBhaban, Farmgate, Dhaka-1215, Bangladesh.

Sarker, M.A.Z., Alam, M.A., Hossain, A. and Mannaf, M.A. 2014. Agro-economic performance of crop diversification in rice based cropping systems of Northwest Bangladesh. Agriculture, Forestry and Fisheries, 3(4): 264-270.

Valdivia, R. and Antle, J.M. 2014. Develop RAPs for use in regional analysis of climate impact and adaptation, in AgMIP Guide for Regional Integrated Assessments: Handbook of Methods and Procedures, Version 5.1(2014), pp. 1-53. 